\title{
1 Spatio-temporal dynamics of growth and death within spherical 2 bacterial colonies
}

3 Anton Welker*1, Marc Hennes*1, Niklas Bender ${ }^{1}$, Tom Cronenberg ${ }^{1}$, Gabriele Schneider ${ }^{1}$,

4 Berenike Maier ${ }^{1,2}$

$5 \quad{ }^{1}$ Institute for Biological Physics, University of Cologne

$6 \quad{ }^{2}$ Center for Molecular Medicine Cologne, University of Cologne

7

*equal contribution

\section{Abstract}

Bacterial growth within colonies and biofilms is heterogeneous. Local reduction of growth rates has been associated with tolerance against various antibiotics. However, spatial gradients of growth rates are poorly characterized in three-dimensional bacterial colonies. Here, we report two spatially resolved methods for measuring growth rates in bacterial colonies. As bacteria grow and divide, they generate a velocity field that is directly related to the growth rates. We derive profiles of growth rates from the velocity field and show that they are consistent with the profiles obtained by single cell counting. Using these methods, we reveal that even small colonies comprising a few thousand cells of the human pathogen Neisseria gonorrhoeae develop a steep gradient of growth rates within two generations. Furthermore, we show that stringent response decelerates growth inhibition at the colony centre. Based on our results, we suggest that aggregation-related growth inhibition can protect gonococci from external stresses even at early biofilm stages. 


\section{Introduction}

As part of their lifestyle, many if not most bacterial species cluster together and form colonies and biofilms. At the surface of biofilms, bacteria have maximum access to environmental nutrients and space for cell growth and division. At the centre of the biofilm, access to nutrients and space are limited. Therefore, we expect that growth and death dynamics depend on position and time (1-6). However, to determine growth rates with spatial resolution it is necessary to track the offspring of a single cell in space and time. This task is technically demanding within three-dimensional biofilms and there are only few reports that systematically characterize growth rates of biofilm associated bacteria with spatio-temporal resolution (7). Measuring generation times in space and time is crucial for understanding the mechanisms of biofilm development and the development of antibiotic tolerance at the centre of biofilms (8-11).

Bacterial growth has been investigated at the colony level by analysing the colony radius $R$ as a function of time $t(3,12,13)$. In young colonies, the colony radius grows exponentially as expected if all cells grow at the same rate. In older colonies, the function $R(t)$ deviates from exponential growth and tends to becomes linear. Simulations indicate that this behaviour is caused by a gradient of growth rates within the colony. Using reporter strains for distinguishing between growing and non-growing cells, it was shown that growth was arrested at the centre of mature biofilms (14-16). However, the corresponding growth rates have not been measured.

Lineage tracking allows for the determination of generation times or growth rates with spatial resolution. Within 2D colonies, individual cell division events are detectable by means of brightfield or fluorescence microscopy and, therefore, lineages arising from a single cell can be tracked $(17,18)$. In 3D colonies, confocal microscopy or light sheet microscopy enable single cell detection within colonies (19-21). Advanced image analysis techniques have been developed for characterizing local order, gene expression, and stress responses with spatial and temporal resolution (22-24). Growth dynamics of Vibrio cholerae has been characterized recently. As a consequence of their rod-like shape, $V$. cholerae shows liquid crystalline order and this structure gives rise to collective, fountain-like motion of bacteria growing in colonies (20). To our knowledge, little work has focussed on the measurement of spatio-temporal growth dynamics within 3D colonies. Given that the size of the bacterial cell body exceeds the limit of optical resolution only $\sim(2-3)$ fold, lineage tracking is technically difficult. A recent study reported growth rates in colonies formed by $V$. cholerae (7). Interestingly, the growth rate was constant throughout the colonies and no spatial gradient was observed. 
In this study, we investigate collective motion and growth dynamics of spherical bacteria (cocci) within spherical colonies. We show that growth generates radial motion and demonstrate that the spatial profile of growth rates can be inferred from the resulting velocity field. In a complementary approach, we determine the growth rate with spatial resolution by counting the offspring of bacteria within the colony. Combining both techniques, we characterize the growth profile within bacterial colonies during biofilm development. At the edge of the colony, the growth rate remains constant for several hours. Within the colony, a gradient of growth rates develops and growth ceases close to the colony centre. We show that inhibition of stringent response accelerates growth inhibition at the colony centre. We conclude that spatial gradients develop rapidly even in relatively small colonies containing several thousands of bacteria.

\section{Colony growth indicates a transition from homogeneous growth to heterogeneous growth.}

In the first step, we characterized the growth of $3 \mathrm{D} \mathrm{wt}^{*}$ gonococcal colonies. Colonies were formed in liquid and subsequently introduced into a flow chamber where growth was monitored for many hours under constant nutrient flow. The radii $R$ of the growing colonies were measured as a function of time. Assuming constant cell density, we derived the number of cells within the colony relative to the number of cells at the start of the experiment $t=0$, $N_{c o l}(t) / N_{c o l}(0)=(R(t) / R(0))^{3}$. The number of cells increased exponentially during the initial $2 \mathrm{~h}$ (Fig. 1). Using an exponential fit $N_{\text {col }}(t) / N_{\text {col }}(0)=\exp \left(\lambda_{\text {colony }} t\right)$ we found that the growth rate was $\lambda_{\text {colony }}=(0.56 \pm 0.01) h^{-1}$. After $2 \mathrm{~h}, N_{\text {col }}(t) / N_{\text {col }}(0)$ deviated from an exponential behaviour. In the next step, $s f g f p$ expressing bacteria ( $w t^{*}$ green) will be used for determining the growth rate at spatial resolution. $s f g f p$ was expressed under the strong pilE promoter to ensure detectability of all fluorescent cells. We assessed whether expression and illumination of the fluorescent marker caused a growth defect by quantifying growth of $w t^{*}$ green colonies and found a transition from exponential growth to sub-exponential growth at the same colony age as for $w t^{*}$ colonies (Fig. 1). The growth rate was $\lambda_{\text {colony }}^{\text {green }}=(0.42 \pm 0.01) h^{-1}$. This difference must be considered in the single cell counting analysis discussed later. 


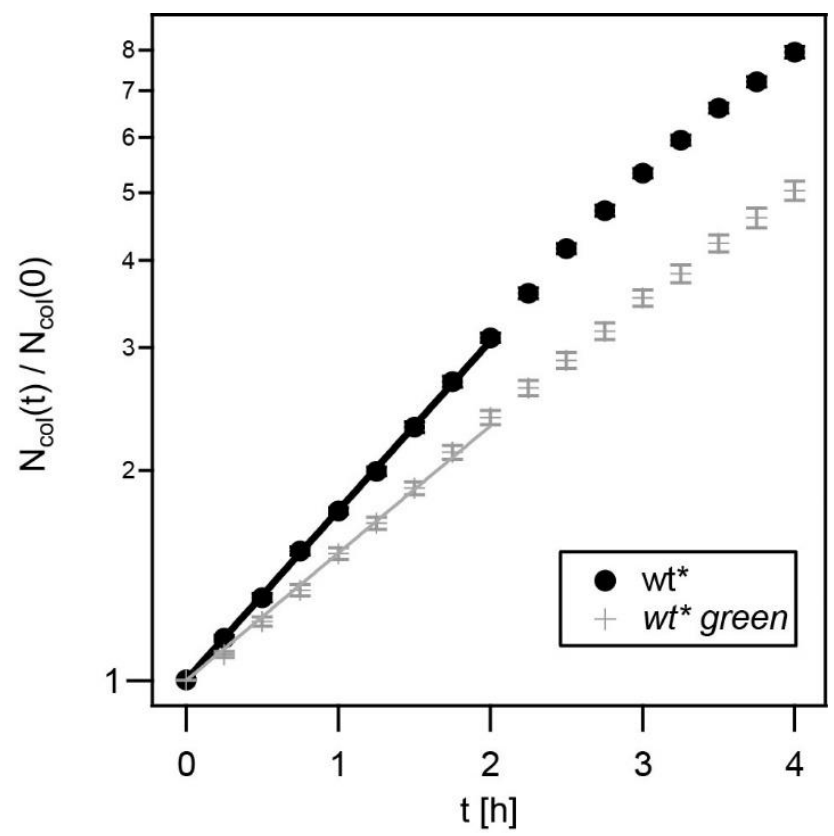

Fig. 1 Expression of $s f g f p$ slightly reduces growth rate. Mean number of cells within colony $N_{\text {col }}(t)$ normalized by the number of cells in the colony at $t=0, N_{\text {col }}(0)$ for wt* $(\mathrm{Ng} 150$, black) and wt* green $(\mathrm{Ng} 194$, grey). Full lines: exponential fits with $N_{\text {col }}(t) / N_{\text {col }}(0)=\exp \left(\lambda_{\text {colony }} t\right) \cdot \lambda_{\text {colony,w } t *}=(0.56 \pm 0.01) h^{-1}$ and $\lambda_{\text {colony,wt*green }}=$ $(0.42 \pm 0.01) h^{-1}$. (mean \pm se, $>40$ colonies for each data point $)$.

Based on the growth analysis at the colony level, we predict that the profile of growth rates is homogeneous during the initial $2 \mathrm{~h}$ of growth and spatial heterogeneity develops after $2 \mathrm{~h}$.

\section{Lineage tracking within 3D colonies.}

We developed a lineage tracking method for measuring growth rates of $N$. gonorrhoeae (gonococcus) within colonies. Recently, the growth rate of rod-shaped cells was measured by quantifying temporal changes in cell length along the major axis of the rod (7). In cocci, this method is hampered by the fact that the change in aspect ratio prior to cell division is small and, additionally, the division plane switches every generation (25). Instead, we track lineages within colonies. N. gonorrhoeae form spherical colonies $(24,26)$. Tracking of all cells individually over multiple generations is prohibited by three factors. Firstly, gonococci are very densely packed (24), and secondly, type 4 pilus mediated interactions between the cells cause them to move actively (27). As a consequence, high time resolution would be necessary to allow for single cell tracking and the associated photodamage would prohibit growth rate analysis.

Furthermore, background fluorescence in colonies consisting exclusively of fluorescent cells would prohibit single cell detection. 
bioRxiv preprint doi: https://doi.org/10.1101/2021.04.27.441609; this version posted April 27, 2021. The copyright holder for this preprint (which was not certified by peer review) is the author/funder, who has granted bioRxiv a license to display the preprint in perpetuity. It is made available under aCC-BY-NC-ND 4.0 International license.

110

111

112

113
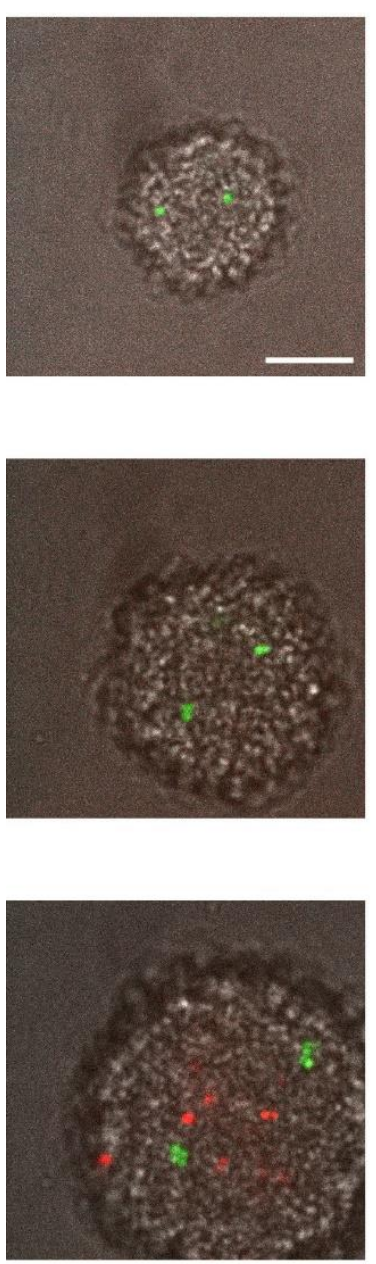
(Fig. 2c, Movie S2).

raw data

To avoid these problems, we tracked the offspring of single or few fluorescent cells. A small fraction of $s f g f p$-expressing cells (wt green) was mixed with non-fluorescent wt* cells. This mixture was inoculated into a flow chamber. Medium was continuously flushed through the chamber, providing constant nutrient and oxygen supply for multiple hours. The medium contained propidium iodide (PI), a fluorescent dye that stains dead cells. The fluorescence signals of growing colonies were detected using confocal microscopy (Fig. 2a). Individual fluorescent cells were identified and their positions within the colonies were determined (Fig. $2 b$, Movie S1). The circumference of the colony was determined using the brightfield images
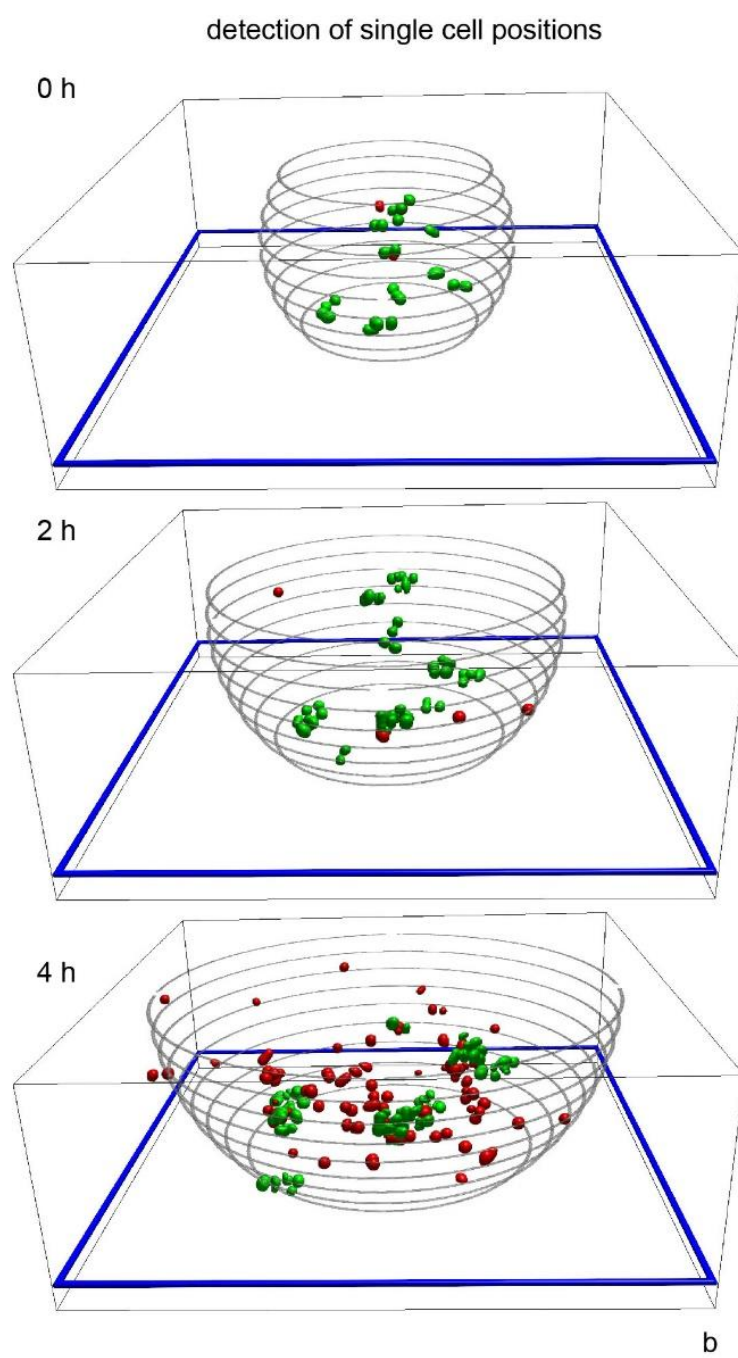

cluster analysis

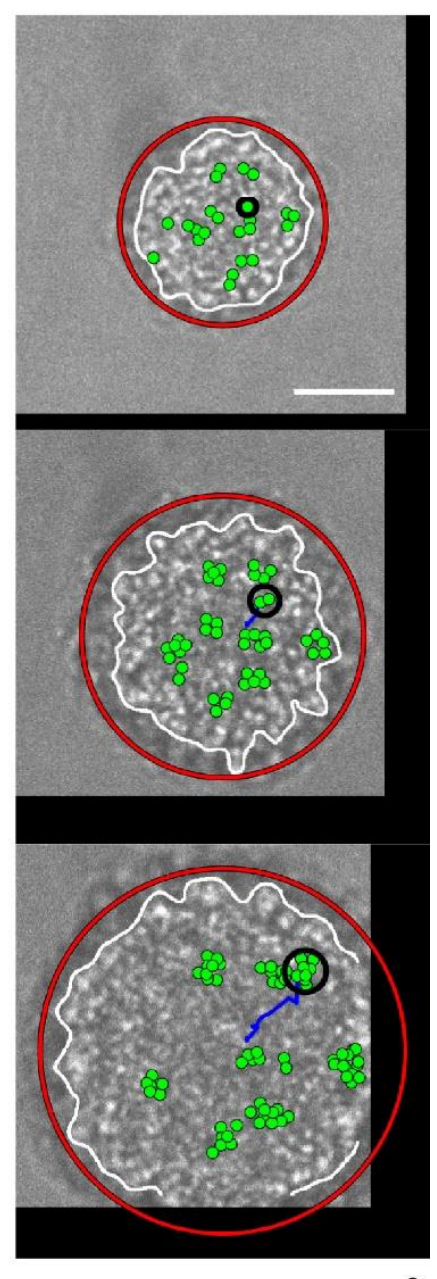

Fig. 2 Lineage tracking in gonococcal colonies. $w t^{*}(\mathrm{Ng} 150)$ mixed with $w t^{*}$ green $(\mathrm{Ng} 194)$. a) Typical confocal plane $(\mathrm{h}=3 \mu \mathrm{m})$ through a colony at different time points. Overlay between brightfield (grey), sfGFP fluorescence (green), and PI fluorescence (red). b) 3D reconstruction of positions of fluorescent cells. The blue frame denotes the plane shown in a). $\Delta \mathrm{h}$ between grey circles: $1 \mu \mathrm{m}$. c) Cluster dynamics in growing colony. Green circles: Positions of wt green gonococci. 3D projections of all wt green cells are shown. Black circle: Circumference of single cluster. Blue line: Trajectory of centre of mass of cluster. White line: Edge of colony. Red circle: Circle depicting radius of colony. Scale bars: $10 \mu \mathrm{m}$. 
A cluster was defined as an assembly of $w t^{*}$ green cells residing in close proximity (Movie S3). Given that only few fluorescent (one percent at the beginning of the experiment) cells were immersed within the colony initially, $w t^{*}$ green cells can be associated with specific clusters. The cells within the cluster are the offspring of a single or few cells contained within the cluster at time $t=0$. In the following two paragraphs, we will describe how the analysis of these clusters allows us to measure the growth rate with spatial resolution. First, we counted the number of cells, $N$, within the cluster, reflecting the growth rate of $w t^{*}$ green cells within the cluster. Second, we analysed the cluster velocity which is influenced by the growth of all cells (mostly $w t^{*}$ cells) residing closer to the colony centre than the cluster and pushing the cluster towards the edge of the colony.

\section{Cell counting (CC) method: Single cell counting reveals that local growth rates decline} rapidly at the centre of growing colonies.

The spatially resolved growth rate was measured by counting the number of $w t^{*}$ green cells within a cluster, $N$, as a function of time. One example of a cluster arising from a single cell is shown in Fig. 3a, b and Movies S2, S3. In this example, the first three cell division events occur nearly simultaneously for all cells belonging to the cluster with a generation time of $\sim 90$ min.

We determined the effective local growth rate $\lambda$ by fitting $N(t+\tau) / N(t)=\exp (\lambda \tau)$ with $\tau=$ $(0-1.5) h$ as described in the Materials and Methods. The growth rate was $\lambda \approx 0.45 h^{-1}$ close to the edge of the colony (Fig. 3c, Fig. S2). This growth rate corresponds to a generation time of $T \approx 1.5 \mathrm{~h}$. While the growth rate at the edge of the colony remained close to $\lambda \approx 0.45 h^{-1}$ up to $4.5 \mathrm{~h}$ after inoculation, the growth rate decreased as a function of the penetration depth into the colony. The spatial profile of growth rates was shallow for young colonies. At $t>2 h$, growth rates dropped severely and growth ceased near the centres of the colonies. The development of heterogeneous growth after $2 \mathrm{~h}$ is consistent with the transition from exponential to linear growth of the colony radius at $2 \mathrm{~h}$ (Fig. 1).

The effective growth rate $\lambda$ depends on cell duplications and on cell death. Therefore, we determined the fractions of dead cells $f_{\text {dead }}=N_{\text {dead }} / N_{\text {total }}$ with spatial and temporal resolution (Fig. 3d). To this end, we added propidium iodide (PI) to the medium. PI stains cells with permeable membranes, indicating cell death. Please note that for determination of $N_{\text {total }}$ we assumed that the density $\rho$ of cells is constant throughout the colony. Within $r_{e} \leq 3 \mu \mathrm{m}$ the cell density is lower compared to the remainder of the colony (Fig. 4c) and, therefore, the fraction 
bioRxiv preprint doi: https://doi.org/10.1101/2021.04.27.441609; this version posted April 27, 2021. The copyright holder for this preprint (which was not certified by peer review) is the author/funder, who has granted bioRxiv a license to display the preprint in perpetuity. It is made available under aCC-BY-NC-ND 4.0 International license.

of dead cells is overestimated in this regime. Most importantly, the fractions of dead cells were $f_{\text {dead }}<5 \%$ for all positions and timepoints. Therefore, the influence of cell death on the changes in $N(t)$ is negligible and the effective growth rate $\lambda$ determined in our experiment is very close to the real growth rate and the term "effective" will be discarded in the following. In older colonies, the fraction of dead cells at the centres of the colonies increased most strongly.
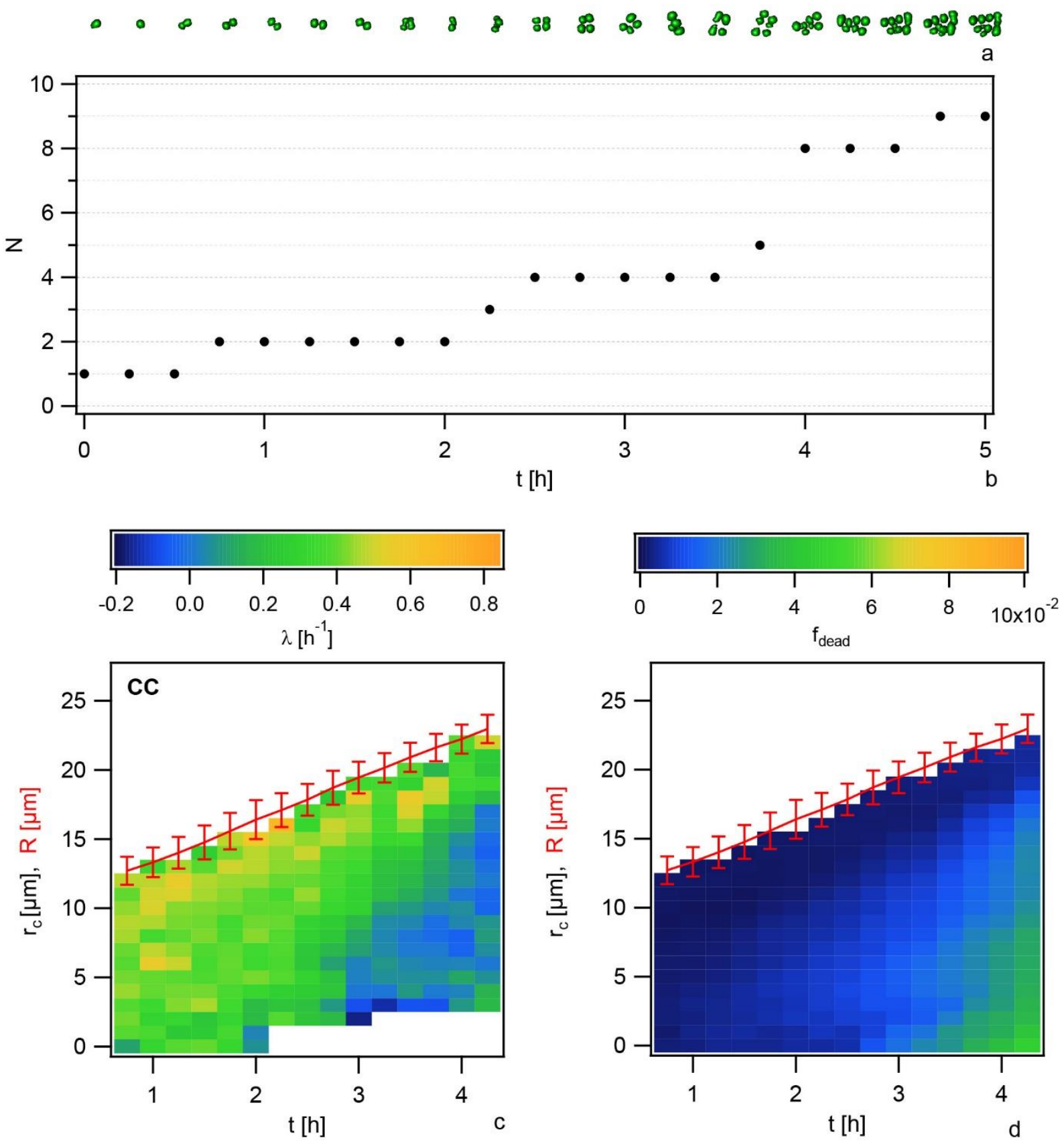

Fig. 3 Spatio-temporal dynamics of growth of $w t^{*}$ green $(\mathrm{Ng} 194)$ mixed with $w t^{*}(\mathrm{Ng} 150)$. a) Example of single growing cluster highlighted in Fig. 2. b) Number of cells $N(t)$ within the cluster shown in a). c) Growth rate $\lambda$ (colour coded) as a function of distance from centre of colony $\left(r_{c}\right)$ and time $t$. d) Fraction of dead cells $f_{\text {dead }}$ (colour coded) as a function of distance from centre of colony $\left(r_{c}\right)$ and time $t$. Red: Mean colony radius ( \pm standard deviation) as a function of time. 
172 In summary, after a short initial period of exponential growth, complex spatio-temporal growth

173 profiles developed within gonococcal colonies with severely reduced growth at the colony 174 centres.

175

176 Velocity field (VF) method: The generation time can be determined from the radial flow 177 of clusters.

178 Cell growth and division generate collective cellular movement directed from the centre of the 179 colony towards its periphery (Fig. 4a). In one- and two-dimensional systems, analysis of this 180 cellular movement has been employed to infer concentration profiles of nutrients and nutrient uptake functions bacterial populations (28). Here, we show that the velocity field can be used for determining the growth rate with spatial resolution in spherical colonies. The velocity of cluster movement $\vec{v}\left(r_{c}\right)$ was determined by analysing the trajectories of the centres of mass of individual clusters (Fig. 4a). Because of the spherical symmetry of the colony, the radial velocity associated with growth is $v\left(r_{c}\right)=\vec{v} \vec{e}_{r}$, i.e. the velocity vector was projected onto the unit vector $\vec{e}_{r}$ pointing from the colony centre towards its edge, yielding the radial component of the cluster velocity $v\left(r_{c}\right) \cdot v\left(r_{c}\right)$ was close to zero at the centre of the colony at $r_{c} \approx 0$ (Fig. $4 a, b)$. With increasing distance from the centre, $r_{c}$, the velocity of clusters increased. At a colony age of less than $2 \mathrm{~h}$, the speed increased linearly as a function of $r_{c}$ with $v\left(r_{c}\right)=$ $(0.17 \pm 0.01) h^{-1} \cdot r_{c}$ (Fig. S3). In older colonies, the speed decreased and $v\left(r_{c}\right)$ became nonlinear consistent with heterogeneous growth. 

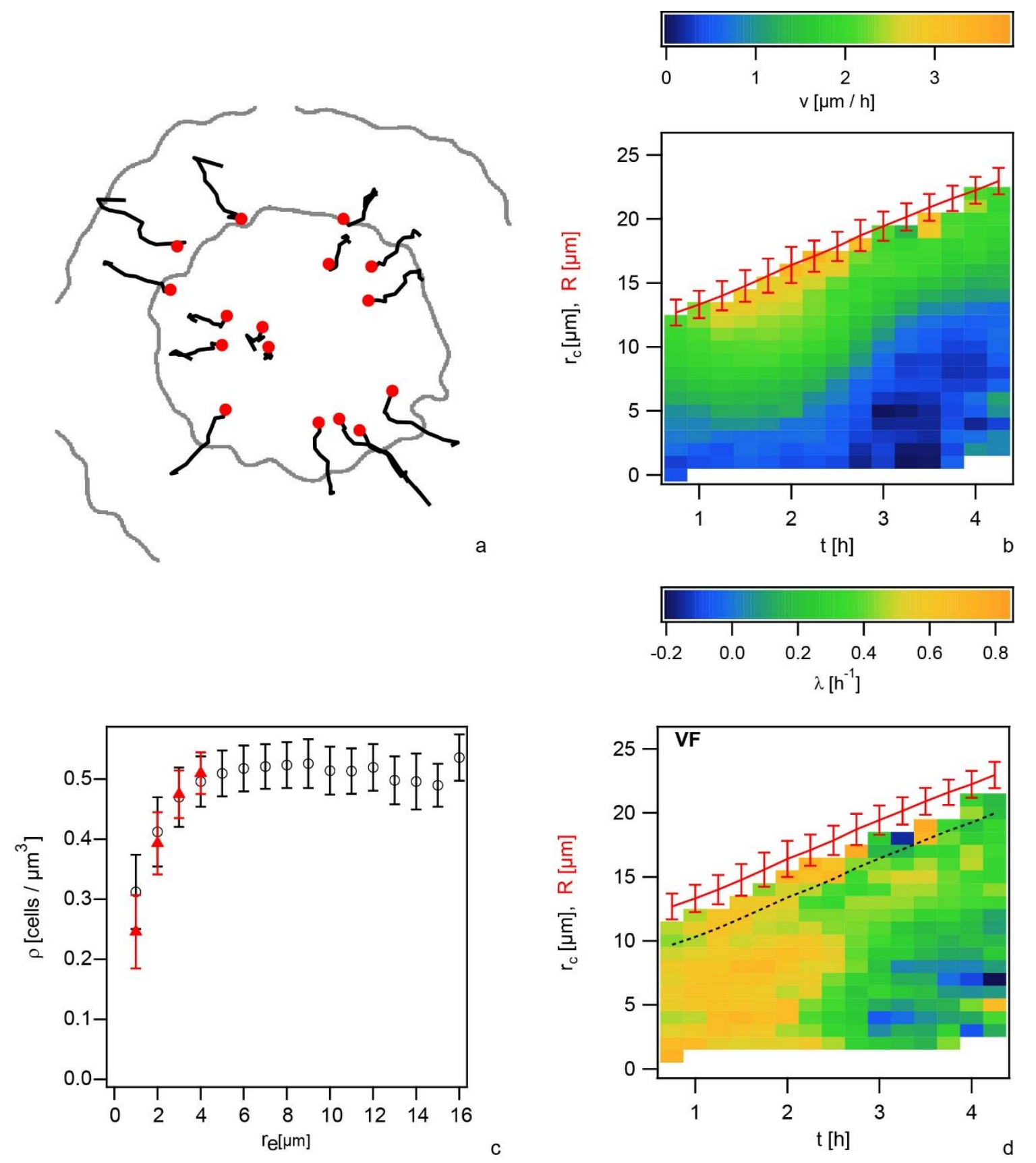

Fig. 4 Growth rates inferred from velocity field of wt* green $(\mathrm{Ng} 194)$ mixed with $\mathrm{wt}^{*}(\mathrm{Ng} 150)$. a) Trajectories of individual clusters moving within one colony acquired over $3 \mathrm{~h}$. Clusters residing at different heights within the colony are projected into one plane. Red circles: Start of trajectory, black lines: trajectories, grey lines: outlines of colony at $0 \mathrm{~h}$ and $3 \mathrm{~h}$, respectively. b) Radial components of cluster velocities $v$ as a function of distance from centre of colony $\left(r_{c}\right)$ and time $t$. Red: Mean colony radius ( \pm standard deviation) as a function of time. c) Cell density $\rho$ profile through colony. Black circles: cylindric coordinates, red triangles: spherical coordinates. d) Growth rates $\lambda$ (colour coded) inferred from velocity field as a function of distance from centre of colony $\left(r_{c}\right)$ and time $t$. Red line: Mean colony radius ( \pm standard deviation) as a function of time. Black dotted line: denotes area in which reduced cell density introduces a systematic error to $\lambda$.

By analysing the flow field $v\left(r_{c}, t\right)$, we can infer the growth rate $\lambda\left(r_{c}, t\right)$. To this end, we formulate the continuity equation with a growth term $\lambda \rho$ which breaks mass conservation

$$
\dot{\rho}=-\vec{\nabla} \cdot(\vec{v} \rho)+\lambda \rho
$$


Here, $\rho(\vec{r}, t)$ is the spatially and temporally varying number density of cells in the colony. We find that the cell density is constant within the colony, but the density decreases at $r_{e} \leq 3 \mu \mathrm{m}$ (Fig. 4c) in agreement with theoretical predictions (29). In the following, we disregard the lowdensity area at the colony edge. First, we consider colonies with an age $t<2 \mathrm{~h}$. During this period of time, the growth rate is nearly constant in space and time. In this regime, eq. 1 simplifies to $\lambda=3 v_{\text {cluster }} / r$. The linear fit shown in Fig. S3a provides $\lambda=(0.51 \pm 0.01) h^{-1}$. This value is slightly higher than the growth rate determined by the CC method (Fig. 3).

Next, we consider older colonies with an age $t>2 \mathrm{~h}$. In these colonies, the growth rate depends on position. By numerically solving eq. 1 and assuming constant $\rho$, i.e. $\partial_{r}\left(r^{2} v_{r}\right)=r^{2} \lambda$, we calculate the growth rate $\lambda\left(r_{e}, t\right)$ (Fig. $\left.4 \mathrm{~d}\right)$. Importantly, we find the same qualitative profiles as by the cell counting method (Fig. 3c, Fig. S3). At $\mathrm{t}<2 \mathrm{~h}$, the growth rates are spatially homogeneous. In older colonies, the growth rate decreases as a function of distance from the edge of the colony. The total growth rates in Fig. $4 d$ are slightly but significantly higher compared to the rates shown in Fig. 3c. The reason for this small quantitative discrepancy can be explained as follows. The velocity of the cluster formed by wt* green cells is determined by all cells residing at a position $r_{c}<r_{c}^{\text {cluster }}$. Given that only $1 \%$ of the cells within the colony was fluorescent, the cluster velocity is determined by the growth of $w t^{*}$. By contrast, the cell counting method used for Fig. 3 relies exclusively on wt* green cells which have a lower growth rate (Fig. 1).

In conclusion, bacteria move radially from the centre towards the periphery of the colony as a consequence of cell growth and the velocity field allows determining the growth rate. This method confirms that a characteristic growth profile develops after only two generations of growth within the colony.

Nutrient supply is nearly saturating. Unexpectedly, the growth rate decreased even within small colonies continuously supplied with rich medium. We hypothesized that either a metabolite or oxygen were depleted at the centres of the colonies. To assess this hypothesis, we increased the flow rate of the medium 5 fold. Indeed, the growth rate increased slightly (Fig. S4, S5). However, the colony radius grew exponentially only for $2 \mathrm{~h}$, indicating that growth became heterogeneous. Reminiscent of the experiments run under standard flow rates, after 2 $\mathrm{h}$ of growth, the growth rate decreased strongly as a function of penetration depth (Fig. S4). This behaviour was observed consistently with the cell counting (CC) method and with the 
velocity field (VF) method. We conclude, therefore, that limitation of nutrients or oxygen is not the main cause for the growth inhibition in gonococcal colonies.

\section{Lack of stringent response influences the spatio-temporal growth dynamics.}

Limitation of nutrients at the centre of colonies is one potential explanation for decreased growth rate. The stringent response is involved in adaptation to nutrient limitation including amino acid, carbon, and fatty acid starvation (30, 31). RelA and SpoT adjust the level of (p)ppGpp, whose accumulation triggers stringent response (32). Deletion of relA suppresses (p)ppGpp production in gonococci and deletion of spoT unmakes the growth defect caused by relA deletion alone (33). We addressed the question whether stringent response affected growth and death in our system. To this end, we mixed $\Delta r e l A \Delta s p o T$ green cells with $\Delta r e l A \Delta s p o T$ cells and characterized the spatio-temporal dynamics of growth and death in these mixed colonies (Fig. 5).

We found that at early time points the growth rates of the $\Delta r e l A \Delta s p o T$ colonies were higher compared to the rates in $w t^{*}$ colonies (Fig. 5, Fig. S5, S6). However, the growth rates dropped even in young colonies after $\mathrm{t}>1 \mathrm{~h}$ at the colony centre (Fig. 5, Fig. S5, S6). This behaviour was found both by the CC method (Fig. 5a), by the VF method (Fig. 5b, c), and by analysing the total number of cells within colonies (Fig. S6). The fraction of dead cells close to the colony centre was higher by a factor of $\sim 2$ in the $\Delta r e l A \Delta s p o T$ compared to the fractions in $w t^{*}$ colonies (Fig. 5d). 

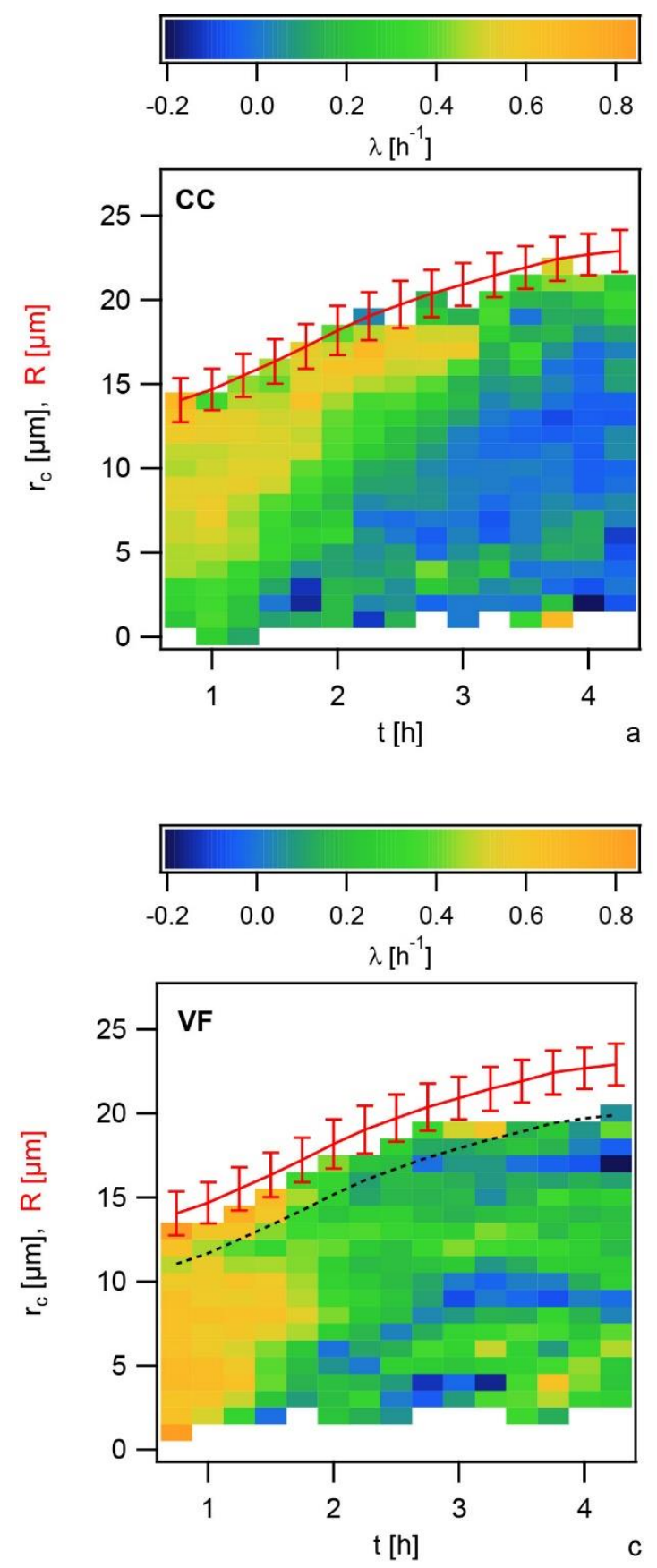

$\lambda\left[\mathrm{h}^{-1}\right]$

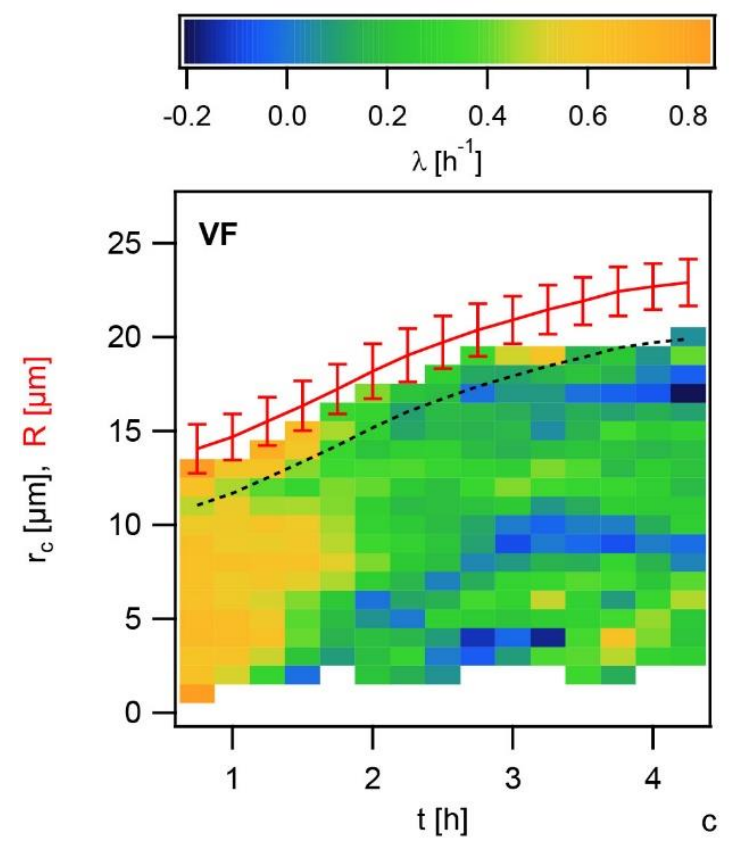

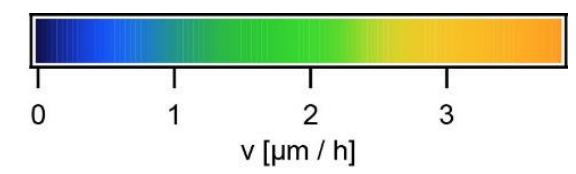
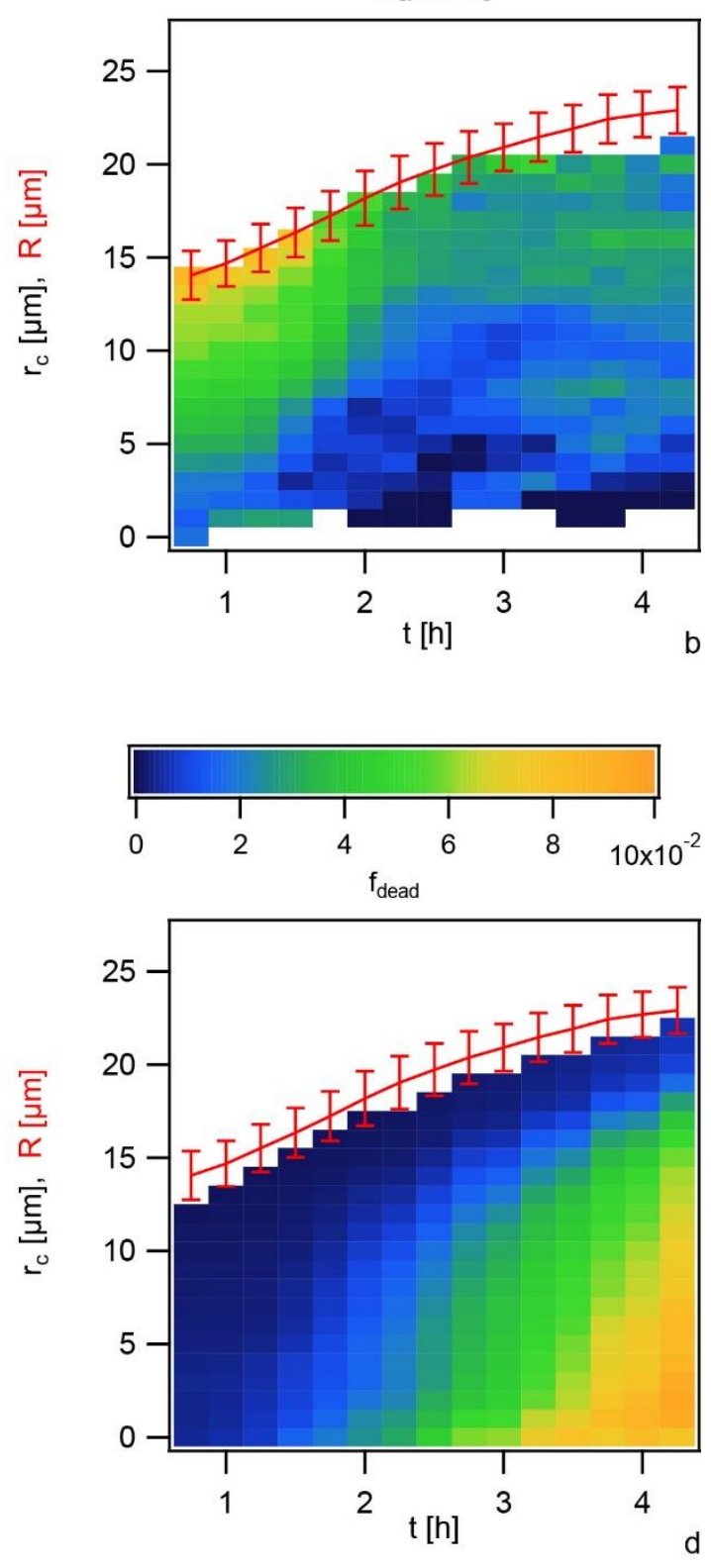

Fig. 5 Stringent response affects growth and death dynamics. ArelA 4 spoT green $(\mathrm{Ng} 224)$ were mixed with $\Delta$ relA $\Delta$ spoT $(\mathrm{Ng} 198)$. a) Growth rate $\lambda$ (colour coded) as a function of distance from centre of colony $\left(r_{c}\right)$ and time $t$. (CC method) b) Radial components of cluster velocities $v$ as a function of of distance from centre of colony $\left(r_{c}\right)$ and time $t$. c) Growth rates $\lambda$ (colour coded) as a function of distance from centre of colony $\left(r_{c}\right)$ and time $t$. Black dotted line: denotes area in which reduced cell density introduces a systematic error to $\lambda$. (VF method) d) Fraction of dead cells $f_{\text {dead }}$ (colour coded) as a function of distance from centre of colony $\left(r_{c}\right)$ and time $t$. Red lines: Mean colony radius ( \pm standard deviation) as a function of time.

Taken together we found that inhibition of stringent response affects growth and death within the colony. Specifically, growth arrest in stringent response deficient colonies occurs prematurely. 


\section{Discussion}

Potentials and limitations of different methods for determining growth rates.

275

Measuring growth rates is tricky and prone to various errors. The classic method for determining growth rates, i.e. the determination of optical density (OD600) as a function of time during bacterial growth, yields the growth rate, aka. Malthusian parameter. While this method is well-accepted, it is prone to various errors often ignored in the literature. For example, adhesion between bacteria and between bacteria and surface reduces the OD600 mimicking reduced growth rates (34). Furthermore, the OD600 can be susceptible to changes in gene expression or changes in cell size affecting the optical properties of the bacteria. One of the most accurate methods for determining relative changes in growth rates through mutations is the competition assay $(35,36)$. But even this method is error-prone; for example, cellular interactions like toxin secretion can falsify the growth rates determined by this method.

The methods introduced here, are based on single cell visualization and, therefore, circumvent the problems described above. We developed two different methods allowing to determine growth rates at spatial resolution. As discussed in the following, both methods implicate complementary advantages and disadvantages. We propose combining both methods to robustly characterize the growth profile within bacterial colonies. First, by counting the number of off-spring of one or few fluorescent cells over short periods of time, the growth rates were determined (CC method). Most importantly, this method allows characterising rates with spatial and temporal resolution. It relies on detection of single cells within a large 3D structure and, therefore, sufficiently strong fluorescence signal of individual cells is essential. To achieve a high signal-to noise ratio, $s f g f p$ was expressed under the control of the strong pilE promoter causing a reduction of growth rate (Fig. 1). Second, we inferred the growth rates from the velocity field caused by cell growth (VF method). This method does not suffer from effects related to $s f g f p$ expression or cell damage by laser light because the fraction of $w t^{*}$ green cells was only $1 \%$ and the velocity field is dominated by $w t^{*}$ cells. However, the method is susceptible to changes in cell density. Under the conditions studied, cell density was constant within the bulk of the colony, but decreased considerably at the edge of the colony. Therefore, the growth rate could not be determined in this region with the second method. Some external stresses cause swelling of cells (21). Swelling would cause the colony to expand and would introduce errors to the determination of growth rates. While both methods have complementary problems, they yield comparable growth profiles. Quantitatively, the VF-method tends to 
provide slightly higher growth rates consistent with the values determined for the total numbers of cells within a colony derived from the colony radii.

Growth of gonococci was considerably more efficient on agar plates. In earlier work, we characterized gonococcal growth in fluorescent colonies on agar plates by quantifying the fluorescence intensity as a function of time $(37,38)$. Exponential colony growth proceeded for many hours and the growth rates were considerably higher. In the agar plate assay, bacteria grew into flat colonies for many generations and this geometric difference together with different concentrations of $\mathrm{O}_{2}$ and $\mathrm{CO}_{2}$ can explain the discrepancy.

\section{Within few generations, growth rates become spatially heterogeneous and stringent response retards development of heterogeneity.}

Rather unexpectedly we found that a characteristic growth profile develops within small gonococcal colonies after no more than two generations under continuous supply of medium optimized for gonococcal growth. The growth rate is constant as a function of time within a 3 $\mu \mathrm{m}$ ring at the periphery of the colony. Remarkably, this is the low-density area. Within the colony, the growth rate decreases continuously as a function of penetration depth and growth stops at a depth of $\sim 10 \mu \mathrm{m}$ corresponding to $\sim 10$ bacteria. Interestingly, this gradient develops even faster when stringent response is inhibited. This result suggests that stringent response drives the cells to reallocate their resources more efficiently to maintain growth within colonies and we conclude that stringent response plays a role in adaptation to life in colonies as shown for biofilms formed by other species (9).

What inhibits growth at the centre of gonococcal colonies? Depletion of nutrients or $\mathrm{O}_{2}$ might be responsible for growth inhibition. Cells residing at the colony edge are likely to deplete nutrients, generating a gradient of nutrient / $\mathrm{O}_{2}$ concentration (28). By increasing the flow rate, nutrient concentrations close to the centres of the colonies would increase. Therefore, we would expect a delay of the onset of growth inhibition. However, we showed that increasing the flow rate did not shift the onset of growth arrest at the centre of the colony considerably. Therefore, we think that mechanical constraints are likely to limit growth within the colony (39-41). Gonococci are tightly packed within colonies with an estimated volume fraction of $\Phi \approx 0.5$ and mechanical stress building up as cells grow, might inhibit cellular proliferation (6). We have shown that freshly assembled colonies rearrange with a relaxation time of $\sim 1$ min (24), suggesting that mechanical constraints should not limit proliferation in young colonies. Future 
studies need to address mechanical properties of older colonies and effects of nutrient limitation on the growth profile.

To our knowledge, growth rates have been determined with spatial resolution only for $V$. cholerae colonies so far (7). There, growth rates were constant even at a penetration depth of $30 \mu \mathrm{m}$. Different bacterial densities and cell shapes may explain the different growth profiles. The volume fraction $\Phi$ of $V$. cholerae of $\Phi \approx 0.2$ (42) was considerably lower compared to $N$. gonorrhoeae. Moreover, for rod-shaped $V$. cholerae orient vertically and move collectively as the colony grows and expands (20). For spherical gonococci, however, we find a radial flow at early times whose speed declines as the colony ages.

\section{Conclusion}

The rapid growth arrest at the centres of the gonococcal colonies suggests that aggregation can rapidly cause tolerance against antibiotics acting on growing bacteria. This is consistent with previous reports showing that gonococcal aggregation enhances their survivability under ceftriaxone treatment with the fraction of dead cells being highest at the colony edge $(21,43)$. Our methods are applicable to all spherical colonies and it will be interesting to compare the growth profiles between different species.

\section{Materials and Methods}

Growth conditions. Gonococcal (GC) base agar was made from $10 \mathrm{~g} / \mathrm{l}$ dehydrated agar (BD Biosciences, Bedford, MA), 5 g/l NaCl (Roth, Darmstadt, Germany), 4 g/l K $2 \mathrm{HPO}_{4}$ (Roth), 1 g/l $\mathrm{KH}_{2} \mathrm{PO}_{4}$ (Roth), $15 \mathrm{~g} / \mathrm{l}$ Proteose Peptone No. 3 (BD Biosciences), $0.5 \mathrm{~g} / \mathrm{l}$ soluble starch (Sigma-Aldrich, St. Louis, MO), and supplemented with 1\% IsoVitaleX (IVX): 1 g/l D-glucose (Roth), 0.1 g/l L-glutamine (Roth), 0.289 g/l L-cysteine-HCL x $\mathrm{H}_{2} \mathrm{O}$ (Roth), $1 \mathrm{mg} / \mathrm{l}$ thiamine pyrophosphate (Sigma-Aldrich), $0.2 \mathrm{mg} / \mathrm{Fe}\left(\mathrm{NO}_{3}\right)_{3}$ (Sigma-Aldrich), $0.03 \mathrm{mg} / \mathrm{l}$ thiamine $\mathrm{HCl}$ (Roth), $0.13 \mathrm{mg} / \mathrm{l}$ 4-aminobenzoic acid (Sigma-Aldrich), $2.5 \mathrm{mg} / \mathrm{l} \beta$-nicotinamide adenine dinucleotide (Roth), and $0.1 \mathrm{mg} / \mathrm{l}$ vitamin B12 (Sigma-Aldrich). GC medium is identical to the base agar composition but lacks agar and starch.

Bacterial strains. All strains used in this study (Table S1) are based on N. gonorrhoeae strain $\mathrm{Ng} 150$ (4), here called $w t^{*}$. In this strain, we deleted the G4 motif responsible for pilin antigenic 
variation. If this motif were present, the primary structure of the major pilin PilE would vary and this variation may affect T4P-T4P interactions and colony dynamics (44).

For construction of $w t^{*}$ green, the pilE promotor region $\left(P_{p i l E}\right)$ was amplified from genomic DNA of strain NG150 ( $\mathrm{GG} 4)$ using primers TC22 (5'AGTTCTTCACCTTTGCTAACCATAAAATTACTCCTAATT GAAAGGGGAAATG-3') and NB065 (5'-TTTTAATTAATTCCGACCCAA TCAACACACCC-3'). The sfgfp gene sequence was amplified from plasmid pET28a-sfgfp (Addgene, Plasmid \#85492) with primers TC21

(5'-CATTTCCCCTTTCAATTAGGAG TAATTTATGGTTAGCAAAGGTGAAGAACT-3') and NB066 (5'TTGGCCGGCCTTATTTATACAGTTCATCCATACCGTG-3'). Both fragments were subsequently merged in a fusion-PCR: fragments were mixed in a 1:1 ratio and a PCR was performed for 20 cycles without the addition of primers. Afterwards, primers NB065 and NB066 were added to the reaction and the PCR was continued for another 20 cycles. The obtained fusion product PpilE-sfgfp was subsequently subcloned into the vector pLAS (38) via FseI and PacI (New England Biolabs) digest. The generated plasmid pLAS-sfgfp was transformed into $E$. coli $\mathrm{DH} 5 \alpha$ and transformants were selected on LB-agar plates containing kanamycin. The correct sequence of the vector insert was verified by sequencing with primers TC19 (5' - CCTTAATTAAGGTTATTTATACAGTTCATCCATACCGTG-3') and TC20 (5'TCTGGCCGGCCTTCCGACCCAATCAACACACC-3'). Finally, the plasmid was transformed into strain NG150 ( $\Delta \mathrm{G} 4)$ to insert the PpilE-sfgfp gene between the lctP and aspC loci. Transformants were selected on GC-agar plates containing spectinomycin. Expression of $s f g f p$ was confirmed via fluorescence microscopy.

Strain $\triangle$ relA $\triangle$ spoT (Ng198) was constructed as follows. Regions upstream and downstream of relA gene were amplified from isolated genomic DNA of strain $\triangle \mathrm{G} 4(\mathrm{Ng} 150)$. PCRs were performed using primers GS_043 (5'-TATGCTGACCGGGGTTTTGG-3') and GS_044 (3'TTAAACCAGTTCCT CTCATCATTTACGGTGCATAGGCGGG-5') for amplification of relA-5'UTR, whereas GS_047 (5'- TGTCTCATTCCGCTTCCGTA GGATAACGCTTCAGACGGCA-3') and GS_048 (3'- GCG GTCGTTAA AACTCCCGAA5') were applied for relA-3'UTR. kanR was amplified from Kanamycin resistant strain $\mathrm{Ng} 050$ $\begin{array}{llll}\text { using } & \text { primers } & \text { GS_045'- }\end{array}$ GAGAGGAACTGGTTTAAATATCGTCGCAAGATGCGGT-3') and GS_046 (3'TACGGAAG CGGAATGAGACA GTCCCGTCAAGTCAGCGTAA-5'). The resulting three single fragments were linked by Fusion-PCR and transformed into strain Ng150. Transformants (Ng197) were selected on GC-agar plates containing kanamycin. Deletion of relA was 
confirmed by sequencing with primers GS_043 (5'- TAT GCTGACCGGGGTTTTGG-3'), GS_045 (5'-GATGAGAGGAACTGGTTTAAATATCG TCGCAAGATG CGGT-3') and GS_046(3'- TACGGAAGCGGAATGAGACAGTCCCGTCAAGTCAGC GTAA-5')

Deletion of spoT was achieved by amplifying spoT-5'UTR from gDNA of $\Delta \mathrm{G} 4$ strain $(\mathrm{Ng} 150)$ with primers GS_037 (5'- TGCGCCGGCAAGTATGAATAC-3') and GS_038 (3'TAATAAGTAAAG CAGGTAAAACGGGTTGC-5'). For amplification of spoT-3'UTR primers GS_041 (5'-CACGAGCT CCTTCAGACGGCTTTCGGGATG-3') and GS_042 (3'GGTTGGAAAATATACAGGTAAAAAATATG TCC-5') were used. Isolated plasmid DNA of ermR-pIGA served as template for amplification of ermC with primers GS_039 (5'TTTACCTGCTTTACTTATTAAATAATTTATAGCTATTGAAAAG-3') and GS_040 (3'GCCGTCTGAAGGAGCTCGTGCTATAATTATAC-5'). PCR-products were merged by Fusion-PCR, transformed strain Ng197 and selected on GC-plates containing erythromycin, resulting in strain $\triangle$ relA $\triangle$ spoT $(\mathrm{Ng} 198)$. Replacement of spoT by ermC was verified via sequencing using primers GS_037 (5'- TGC GCCGGCAAGTATGAATAC-3'), GS_049 (5'ATTGCCGAACCCGCCGTTCT-3'), GS_050 (5 '-GCA AACCCGTATTCCACGAT-3') and GS_51 (5'-CGGTCGGTTTGTTATTGCGG-3').

sfgfp is expressed under the control of the pilE promoter with has high expression levels. We investigated whether $s f g f p$ expression affects the growth rate of gonococci in our assay by comparing the number of cells per colonies $N_{\text {col }}(t)$ as a function of time (Fig. 1). We found that the growth rate of $w t^{*}$ green cells expressing $s f g f p$ is $14 \%$ lower compared to $w t^{*}$ cells that do not express fluorescent proteins. Therefore, the growth rate determined by counting the number of $w t^{*}$ green cells per cluster, $N(t)$, is expected to be lower compared to the growth rate determined from colony growth during the exponential phase in agreement with Fig. 3a.

Confocal microscopy. $w t^{*}$ and $w t^{*}$ green cells were grown for $14 \mathrm{~h}$ on $\mathrm{GC}+$ IsoVitaleX plates at $37^{\circ} \mathrm{C}, 5 \% \mathrm{CO}_{2}$ and re-suspended in $5 \mathrm{~mL} \mathrm{GC}+\mathrm{IVX}$ medium at an OD 0.1 . The ratio of nonfluorescent $w t^{*}$ and fluorescent $w t^{*}$ green cells was set to 100:1. Supplementation of $100 \mu \mathrm{L}$ miliQ water dissolves existing bacterial colonies and shaking at $37^{\circ} \mathrm{C}, 5 \% \mathrm{CO} 2$ for 30 minutes allows for colony reassembly. From this suspension, $250 \mu \mathrm{L}$ are injected into a microfluidic flow chamber (Ibidi Luer $0.8 \mathrm{~mm}$ channel height + Ibitreat) connected to a peristaltic pump (model 205U; Watson Marlow, Falmouth, United Kingdom) for constant nutrient supply of 1 rpm (standard flow rate) or $5 \mathrm{rpm}$ (five-fold flow rate) $(\mathrm{GC}+\mathrm{IVX}+0.004 \% \mathrm{PI})$. Prior usage, all flow chambers were coated with Poly-L-Lysine (Sigma, Cat. No. P4832, $50 \mu \mathrm{g} / \mathrm{ml}$ ). 
Images were acquired using an inverted microscope (Ti-E, Nikon) equipped with a spinning disc confocal unit (CSU-X1, Yokogawa) and a 100x, 1.49 NA, oil immersion objective lens. The excitation wave lengths were 488 and $561 \mathrm{~nm}$. The sfGFP signal of the cells and a brightfield image were recorded for $5 \mathrm{~h}$ every $15 \mathrm{~min}$. Starting from the surface of the glass coverslide, $40 \mu \mathrm{m} \times 40 \mu \mathrm{m} \times 25 \mu \mathrm{m}$ large image stacks with a voxel size of $0.08 \mu \mathrm{m} \times 0.08 \mu \mathrm{m} \times 0.4 \mu \mathrm{m}$ were acquired.

Detection of single cell positions and cluster analysis. Bright-field images were used to determine the colonies' centers of mass and radius. For this purpose, a circle was fitted to the colony contour, which is determined by a threshold applied on the filtered bright-field images. The height of the center of mass of the colony was estimated with $0.85 \mathrm{x}$ colony radius.

From the confocal image stacks, single cell positions of $w t^{*}$ green cells were determined. All confocal images were registered using the center of mass of the colony and stretched by a factor of 3 in z-direction to obtain spherical intensity profiles of all particles. Every image voxel was taken to the power of 3 to increase the image contrast. The mean intensity profile of several different monococci inside bacterial colonies were used to generate a symmetrical 3D kernel for convolution of all images. Spheroidal features were found using the MATLAB feature3d function written by Yongxiang Gao and Maria Kilfoil (45) based on IDL code written by John C. Crocker and David G. Grier (46). Clusters are defined by spheroidal features, which are less than $2 \mu \mathrm{m}$ apart from each other. Because the number of clusters is much smaller compared to the number of features, clusters can be tracked by the MATLAB trackmem function written by Maria Kilfoil, again based on IDL code written by John C. Crocker. We applied the tracking algorithm to cluster positions located in time intervals $[t, t+1.5 \mathrm{~h}]$ with $\mathrm{t} \in[0 \mathrm{~h}: 0.25 \mathrm{~h}: 3 \mathrm{~h}]$. Only trajectories with a length of $1.5 \mathrm{~h}$ were used for further analysis.

We derived the mean growth rate as a function of the distance $r_{e}$ from the edge of the colony by fitting $\left\langle N^{*}\left(r_{e}, t+\tau\right)\right\rangle=\exp (\lambda \tau)$, where $N^{*}$ is the normalized and averaged data of individual clusters within position intervals $\left[r_{e}, r_{e}+2 \mu \mathrm{m}\right]$ within $1.5 \mathrm{~h}$ time intervals. The mean distance to the colony edge was defined for each cluster by averaging every distance to the colony edge within the $1.5 \mathrm{~h}$ time intervals. The velocity of each cluster depends on the distance to the centre of mass of the colony. Hence, we sorted the data relative to the colony centre of mass in the intervals $\left[r_{c}, r_{c}+2 \mu m\right]$. In general, we did not select for a specific colony size. However, it was necessary for the heatmaps illustrations. Hence, we determined the mean colony radius $R$ and its standard deviation at every timepoint. Colonies, which were larger or 
smaller than a standard deviation from the mean colony radius were discarded. Growth rates were plotted relative to the mean colony radius and velocities were plotted relative to the centre of mass of the colonies.

To assess the robustness of our algorithm with respect to the order of data averaging and exponential fitting, we fitted the $N(t)$ data of individual clusters as follows. To obtain Fig. S1, we derived growth rates of single clusters by fitting an exponential function $\frac{N(t+\tau)}{N_{0}(t)}=\exp (\lambda \tau)$ to the number of cells, $N$, inside a cluster within the time interval indicated. The medians of the distributions in Fig. S1 agree well with the data shown in Fig. 3c. We note, however, that there are pronounced peaks at $l_{\text {single }}=0$, indicating that some clusters do not start replicating.

Determination of growth rate from velocity fields. The growth rate $\lambda$ was calculated by $\lambda=$ $\operatorname{div}(v)=2 * \frac{v}{r_{c}}+\frac{d v}{d r_{c}}$ using spherical coordinates. Given the velocities shown in the heat maps, the previous equation simplifies to $\lambda(r)=2 * \frac{v(r)}{r_{c}(r)}+\frac{v(r-1)-v(r+1)}{2 \mu m}$. Thus, the growth rates were directly calculated from the velocities given in the heatmaps.

Determination of fraction of dead cells. The medium (GC + IVX) which was continuously supplied to the flow chamber, was supplemented with $0.004 \%$ PI (propidium iodide) to stain dead cells during image acquisition. Spheroidal features (dead cells) were detected using the same method as described in the previous paragraph for detecting living cells. The number of dead cells, $\delta$, was normalized: $\delta^{*}(r)=\frac{\delta(r)}{\rho(r) V(r)}$, where the cell density $\rho(r)$ is set to be constant (19). Due to a lower cell density up to $2 \mu \mathrm{m}$ away from the colony edge, the fraction of dead cells is underestimated there. The volume of interest $V\left(r_{e}\right)$ is determined as a function of the distance from the colony edge $r_{e}$ within $\left[r_{e}, r_{e}+2 \mu m\right]$. For better comparison between the heat maps, the fractions of dead cells were averaged within $1.5 \mathrm{~h}$ time intervals.

\section{Acknowledgements}

We thank Sebastian Kraus for help with strain construction, and Jens Elgeti, George O'Toole, and the Maier lab for helpful discussions. This work was supported by the Deutsche Forschungsgemeinschaft through grants MA3898 and CRC1310, and the Center for Molecular Medicine Cologne. 
bioRxiv preprint doi: https://doi.org/10.1101/2021.04.27.441609; this version posted April 27, 2021. The copyright holder for this preprint (which was not certified by peer review) is the author/funder, who has granted bioRxiv a license to display the preprint in perpetuity. It is made available under aCC-BY-NC-ND 4.0 International license.

499

500 Competing interests

501 The authors declare no competing interests. 


\section{References}

504

505

506

507

508

509

510

511

512

513

514

515

516

517

518

519

520

521

522

523

524

525

526

527

528

529

530

531

532

533

534

535

1. Kim W, Racimo F, Schluter J, Levy SB, \& Foster KR (2014) Importance of positioning for microbial evolution. Proc Natl Acad Sci U S A 111(16):E1639-1647.

2. Farrell FDC, Hallatschek O, Marenduzzo D, \& Waclaw B (2013) Mechanically Driven Growth of Quasi-Two-Dimensional Microbial Colonies. Phys Rev Lett 111(16).

3. Tjhung E \& Berthier L (2020) Analogies between growing dense active matter and soft driven glasses. Phys Rev Res 2(4).

4. Zollner R, Oldewurtel ER, Kouzel N, \& Maier B (2017) Phase and antigenic variation govern competition dynamics through positioning in bacterial colonies. Sci Rep-Uk 7.

5. Wang X, Stone HA, \& Golestanian R (2017) Shape of the growing front of biofilms. New J Phys 19.

6. Maier B (2021) How Physical Interactions Shape Bacterial Biofilms. Annu Rev Biophys.

7. Hartmann R, et al. (2019) Emergence of three-dimensional order and structure in growing biofilms. Nat Phys 15(3):251-256.

8. Hall CW \& Mah TF (2017) Molecular mechanisms of biofilm-based antibiotic resistance and tolerance in pathogenic bacteria. FEMS Microbiol Rev 41(3):276-301.

9. Nguyen D, et al. (2011) Active starvation responses mediate antibiotic tolerance in biofilms and nutrient-limited bacteria. Science 334(6058):982-986.

10. Yan J \& Bassler BL (2019) Surviving as a Community: Antibiotic Tolerance and Persistence in Bacterial Biofilms. Cell Host Microbe 26(1):15-21.

11. Balaban NQ, et al. (2019) Definitions and guidelines for research on antibiotic persistence. Nat Rev Microbiol 17(7):441-448.

12. Freyer JP \& Sutherland RM (1986) Regulation of growth saturation and development of necrosis in EMT6/Ro multicellular spheroids by the glucose and oxygen supply. Cancer Res 46(7):3504-3512.

13. Radszuweit M, Block M, Hengstler JG, Scholl E, \& Drasdo D (2009) Comparing the growth kinetics of cell populations in two and three dimensions. Phys Rev E 79(5).

14. Sternberg C, et al. (1999) Distribution of bacterial growth activity in flow-chamber biofilms. Appl Environ Microbiol 65(9):4108-4117.

15. Teal TK, Lies DP, Wold BJ, \& Newman DK (2006) Spatiometabolic stratification of Shewanella oneidensis biofilms. Appl Environ Microbiol 72(11):7324-7330.

16. Stewart PS \& Franklin MJ (2008) Physiological heterogeneity in biofilms. Nat Rev Microbiol 6(3):199-210. 
17. van Vliet S, et al. (2018) Spatially Correlated Gene Expression in Bacterial Groups: The Role of Lineage History, Spatial Gradients, and Cell-Cell Interactions. Cell Syst 6(4):496-507 e496.

18. Leygeber M, et al. (2019) Analyzing Microbial Population Heterogeneity-Expanding the Toolbox of Microfluidic Single-Cell Cultivations. J Mol Biol 431(23):4569-4588.

19. Drescher K, et al. (2016) Architectural transitions in Vibrio cholerae biofilms at singlecell resolution. P Natl Acad Sci USA 113(14):E2066-E2072.

20. Qin B, et al. (2020) Cell position fates and collective fountain flow in bacterial biofilms revealed by light-sheet microscopy. Science 369(6499):71-77.

21. Cronenberg T, Hennes M, Wielert I, \& Maier B (2021) Antibiotics modulate attractive interactions in bacterial colonies affecting survivability under combined treatment. PLoS Pathog 17(2):e1009251.

22. Hartmann R, et al. (2021) Quantitative image analysis of microbial communities with BiofilmQ. Nat Microbiol 6(2):151-156.

23. Yan J, Sharo AG, Stone HA, Wingreen NS, \& Bassler BL (2016) Vibrio cholerae biofilm growth program and architecture revealed by single-cell live imaging. Proc Natl Acad Sci U S A 113(36):E5337-5343.

24. Welker A, et al. (2018) Molecular Motors Govern Liquidlike Ordering and Fusion Dynamics of Bacterial Colonies. Phys Rev Lett 121(11):118102.

25. Saraiva BM, et al. (2020) Reassessment of the distinctive geometry of Staphylococcus aureus cell division. Nat Commun 11(1):4097.

26. Higashi DL, et al. (2007) Dynamics of Neisseria gonorrhoeae attachment: microcolony development, cortical plaque formation, and cytoprotection. Infect Immun 75(10):47434753.

27. Craig L, Forest KT, \& Maier B (2019) Type IV pili: dynamics, biophysics and functional consequences. Nat Rev Microbiol 17(7):429-440.

28. Hornung R, et al. (2018) Quantitative modelling of nutrient-limited growth of bacterial colonies in microfluidic cultivation. J R Soc Interface 15(139).

29. Ponisch W, Weber CA, Juckeland G, Biais N, \& Zaburdaev V (2017) Multiscale modeling of bacterial colonies: how pili mediate the dynamics of single cells and cellular aggregates. New J Phys 19.

30. Hauryliuk V, Atkinson GC, Murakami KS, Tenson T, \& Gerdes K (2015) Recent functional insights into the role of (p)ppGpp in bacterial physiology. Nature Reviews Microbiology 13(5):298-309.

31. Navarro Llorens JM, Tormo A, \& Martinez-Garcia E (2010) Stationary phase in gramnegative bacteria. FEMS Microbiol Rev 34(4):476-495.

32. Magnusson LU, Farewell A, \& Nystrom T (2005) ppGpp: a global regulator in Escherichia coli. Trends Microbiol 13(5):236-242. 
33. Fisher SD, Reger AD, Baum A, \& Hill SA (2005) RelA alone appears essential for (p)ppGpp production when Neisseria gonorrhoeae encounters nutritional stress. Fems Microbiol Lett 248(1):1-8.

34. Carbonnelle E, Helaine S, Nassif X, \& Pelicic V (2006) A systematic genetic analysis in Neisseria meningitidis defines the Pil proteins required for assembly, functionality, stabilization and export of type IV pili. Mol Microbiol 61(6):1510-1522.

35. Chevin LM (2011) On measuring selection in experimental evolution. Biol Lett $7(2): 210-213$.

36. Ram Y, et al. (2019) Predicting microbial growth in a mixed culture from growth curve data. Proc Natl Acad Sci U S A 116(29):14698-14707.

37. Oldewurtel ER, Kouzel N, Dewenter L, Henseler K, \& Maier B (2015) Differential interaction forces govern bacterial sorting in early biofilms. Elife 4.

38. Kouzel N, Oldewurtel ER, \& Maier B (2015) Gene Transfer Efficiency in Gonococcal Biofilms: Role of Biofilm Age, Architecture, and Pilin Antigenic Variation. J Bacteriol 197(14):2422-2431.

39. Warren MR, et al. (2019) Spatiotemporal establishment of dense bacterial colonies growing on hard agar. Elife 8.

40. Delarue M, et al. (2016) Self-driven jamming in growing microbial populations. Nature Physics 12(8):762-766.

41. Tuson HH, et al. (2012) Measuring the stiffness of bacterial cells from growth rates in hydrogels of tunable elasticity. Mol Microbiol 84(5):874-891.

42. Vidakovic L, Singh PK, Hartmann R, Nadell CD, \& Drescher K (2018) Dynamic biofilm architecture confers individual and collective mechanisms of viral protection. Nature Microbiology 3(1).

43. Wang LC, Litwin M, Sahiholnasab Z, Song W, \& Stein DC (2018) Neisseria gonorrhoeae Aggregation Reduces Its Ceftriaxone Susceptibility. Antibiotics (Basel) $7(2)$.

44. Rotman E \& Seifert HS (2014) The Genetics of Neisseria Species. Annu Rev Genet 48:405-431.

45. Gao X \& Kilfoil ML (2009) Accurate detection and complete tracking of large populations of features in three dimensions. Optics Express 17(6):4685.

46. Crocker JC \& Grier DG (1996) Methods of Digital Video Microscopy for Colloidal Studies. J. Colloid Interface Sci. 179:298. 


\section{Supplementary Figures}

611
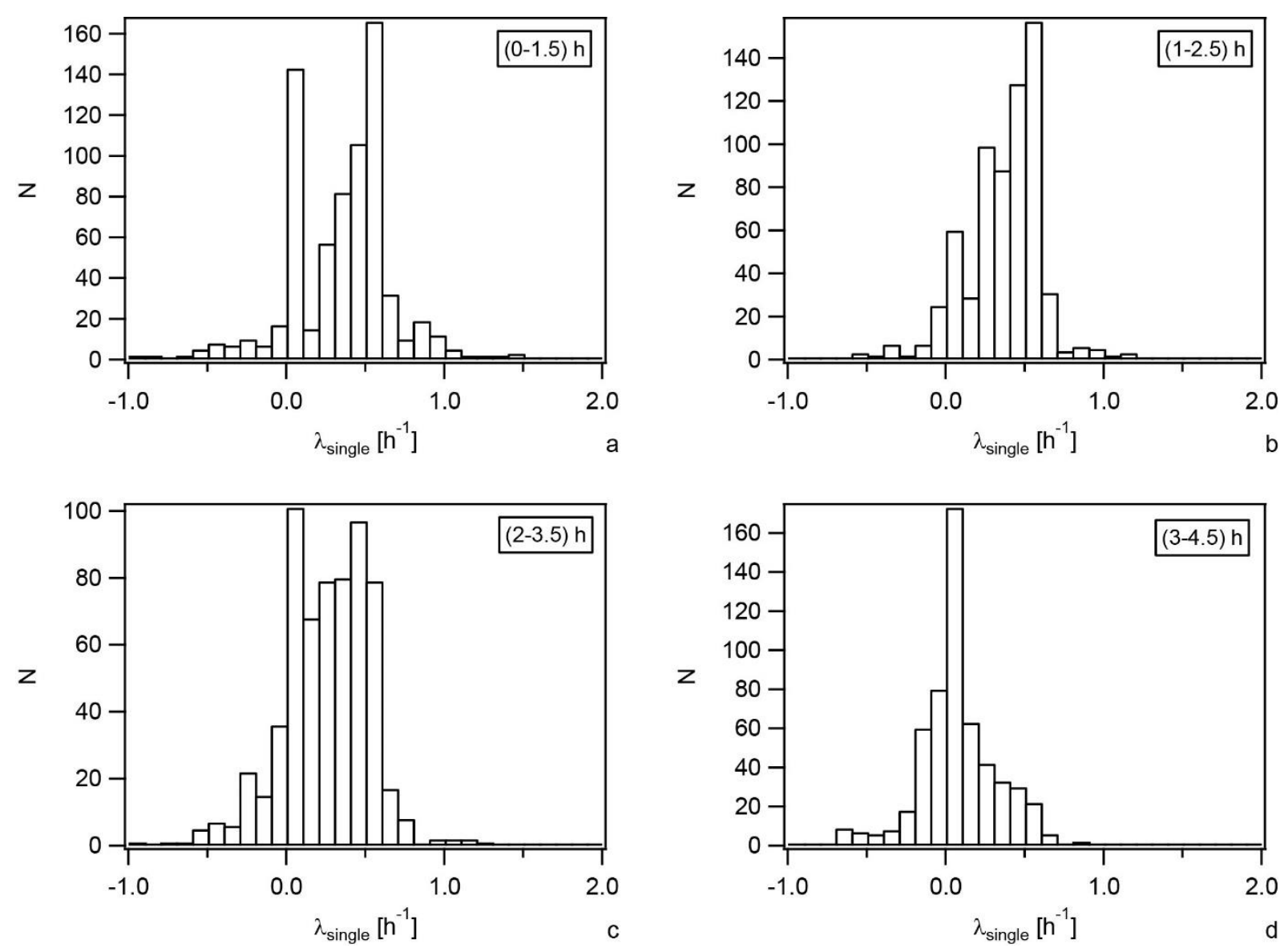

Fig. S1 Effect of data averaging and fitting on determination of growth ratesfor $w t^{*}$ green

614 (Ng194) mixed with $w t^{*}(\mathrm{Ng} 150)$. Histogram of growth rates obtained from single clusters by

615 fitting over different time intervals of $1.5 \mathrm{~h}$ length as described in the Methods section. Please note that all growth rates shown in the main text have been obtained differently. 


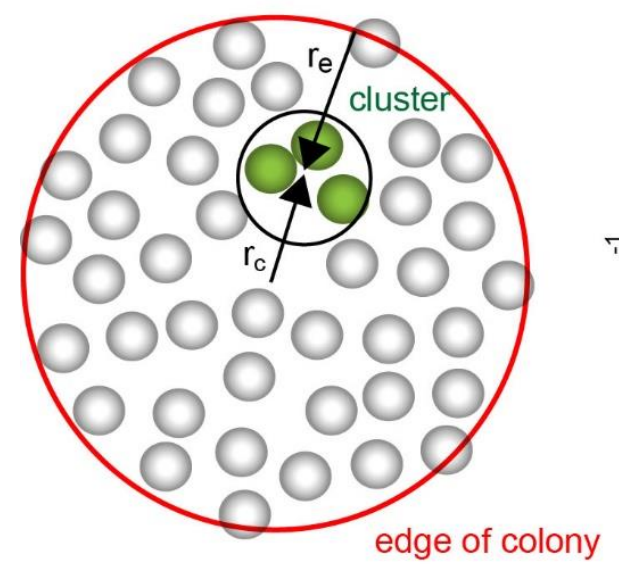

a

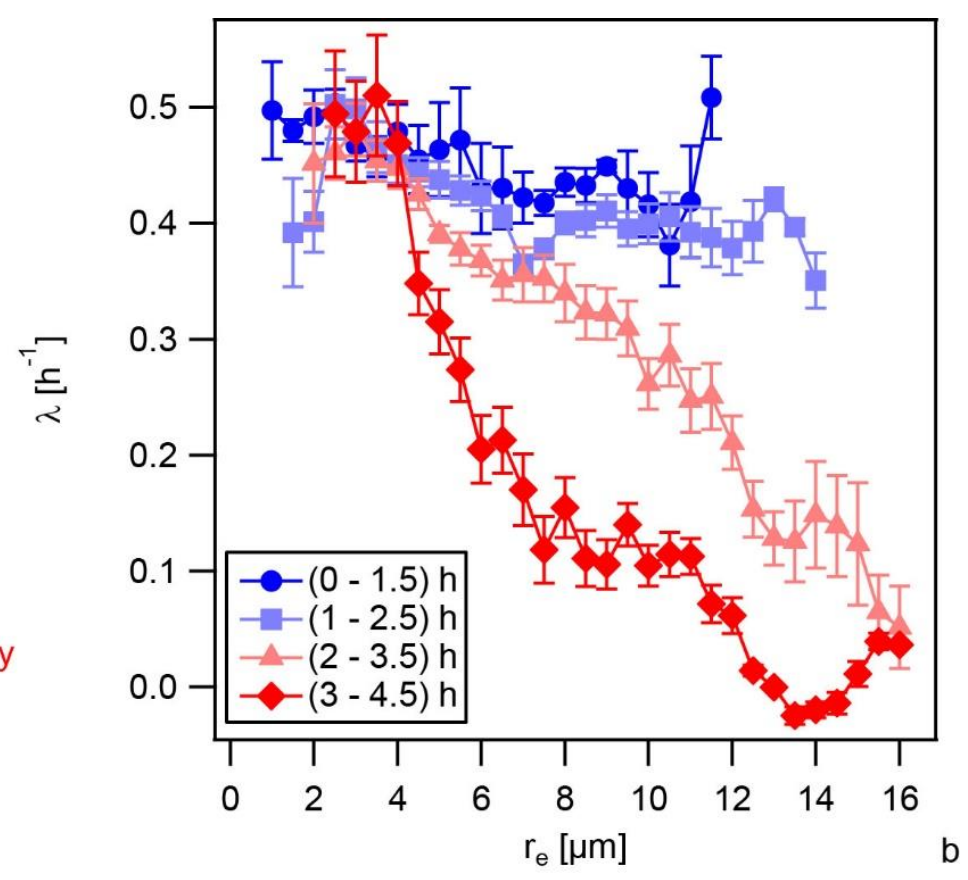

620 Fig. S2 Growth rate in numbers determined from cell counting within clusters (CC method) of $621 w t^{*}$ green $(\mathrm{Ng} 194)$ mixed with $w t^{*}(\mathrm{Ng} 150)$. a) Sketch of colony with distance to edge, $r_{e}$, and 622 distance to centre, $r_{e}$. b) Mean growth rate $\lambda$ as a function of the distance $r_{e}$ from the edge of 623 the colony (mean \pm se, $10-285$ clusters for each data point). 

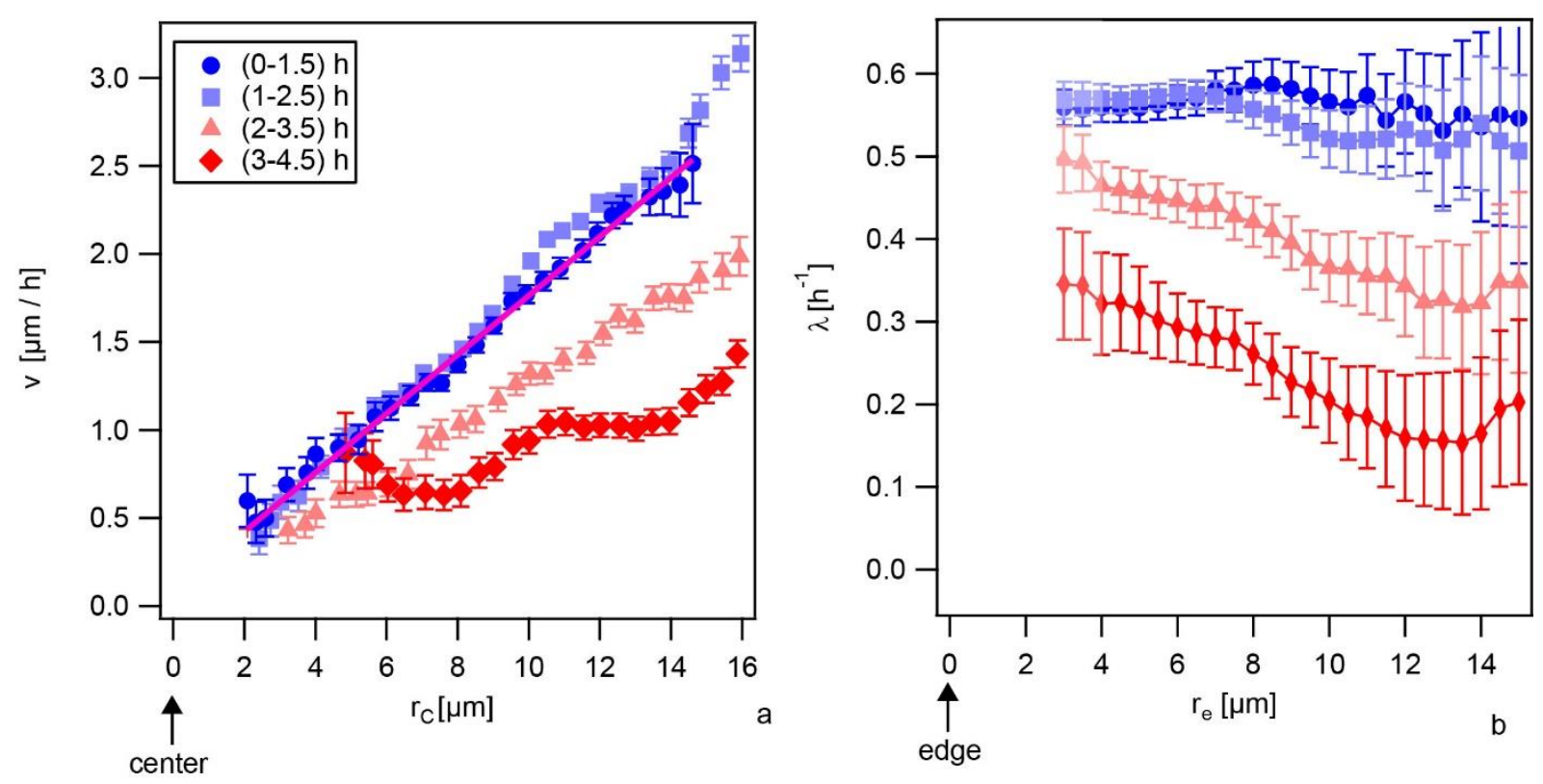

627 Fig. S3 Growth rate in numbers determined from velocity field of clusters (VF method) of $w t^{*}$ 628 green $(\mathrm{Ng} 194)$ mixed with $w t^{*}(\mathrm{Ng} 150)$. Sketch of colony with distance to edge, $r_{e}$, and distance 629 to centre, $r_{e}$ a) Velocity of cluster $v$ determined during different periods of time. Pink full line: 630 Linear fit to $v\left(r_{c}\right)$ for $(0-1.5) \mathrm{h}$. b) Growth rates inferred from velocity field as a function of 631 the distance from the edge of the colony, $r_{e}$ (mean \pm se, $10-212$ clusters). 

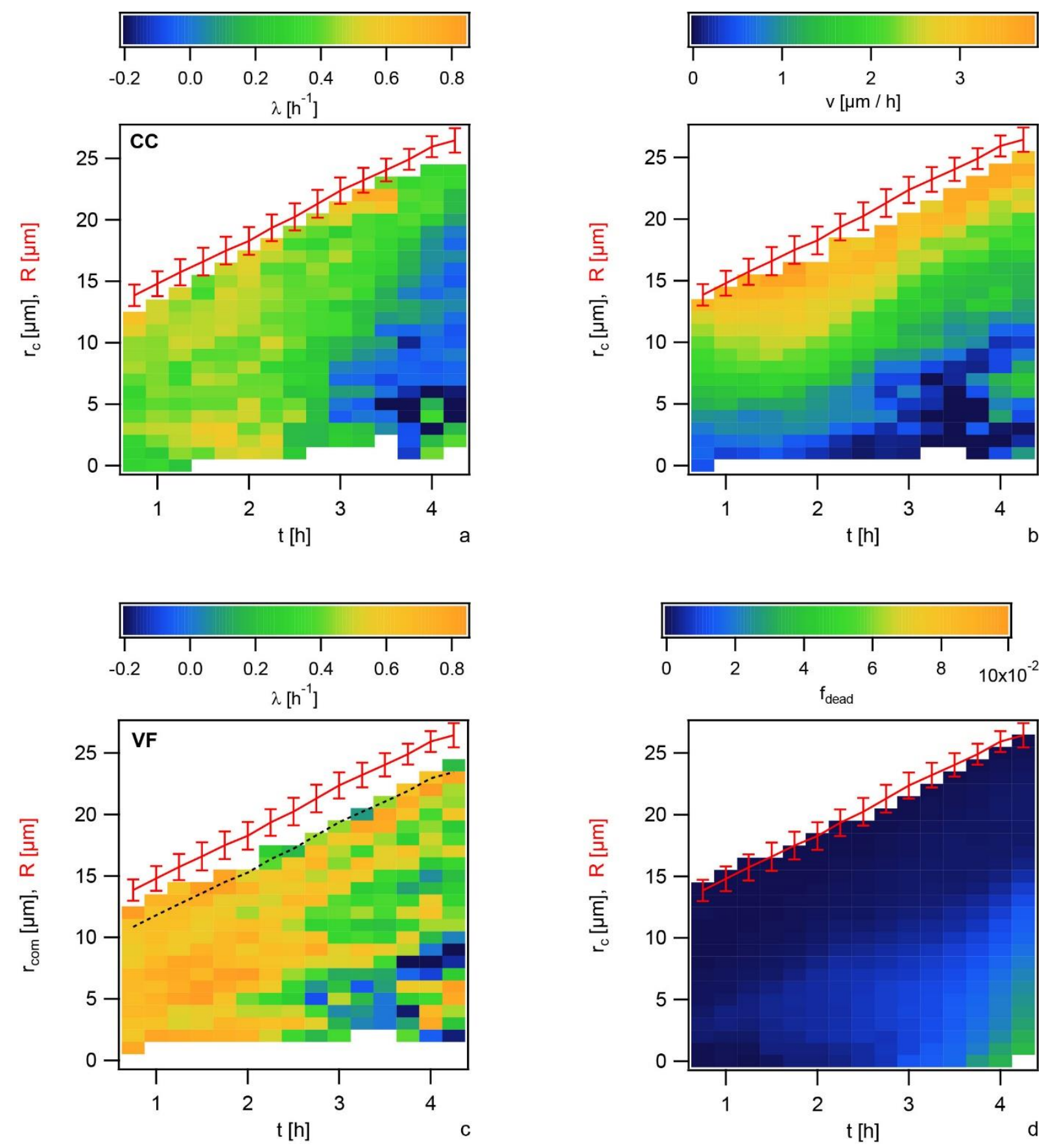

634 Fig. S4 Spatio-temporal dynamics of growth of $w t^{*}$ green $(\mathrm{Ng} 194)$ mixed with $w t^{*}(\mathrm{Ng} 150)$ at

635 five-fold higher flow rate as compared to experiments described in Figs 3, 4. a) Growth rate $\lambda$

636 (colour coded) as a function of distance from centre of colony $\left(r_{c}\right)$ and time $t$. (CC method) b)

637 Radial components of cluster velocities $v$ as a function of of distance from centre of colony $\left(r_{c}\right)$

638 and time $t$. c) Growth rates $\lambda$ (colour coded) as a function of distance from centre of colony $\left(r_{c}\right)$

639 and time $t$. Black dotted line: denotes area in which reduced cell density introduces a systematic

640 error to $\lambda$. (VF method) d) Fraction of dead cells $f_{\text {dead }}$ (colour coded) as a function of distance

641 from centre of colony $\left(r_{c}\right)$ and time $t$. Red lines: Mean colony radius ( \pm standard deviation) as

642 a function of time. 

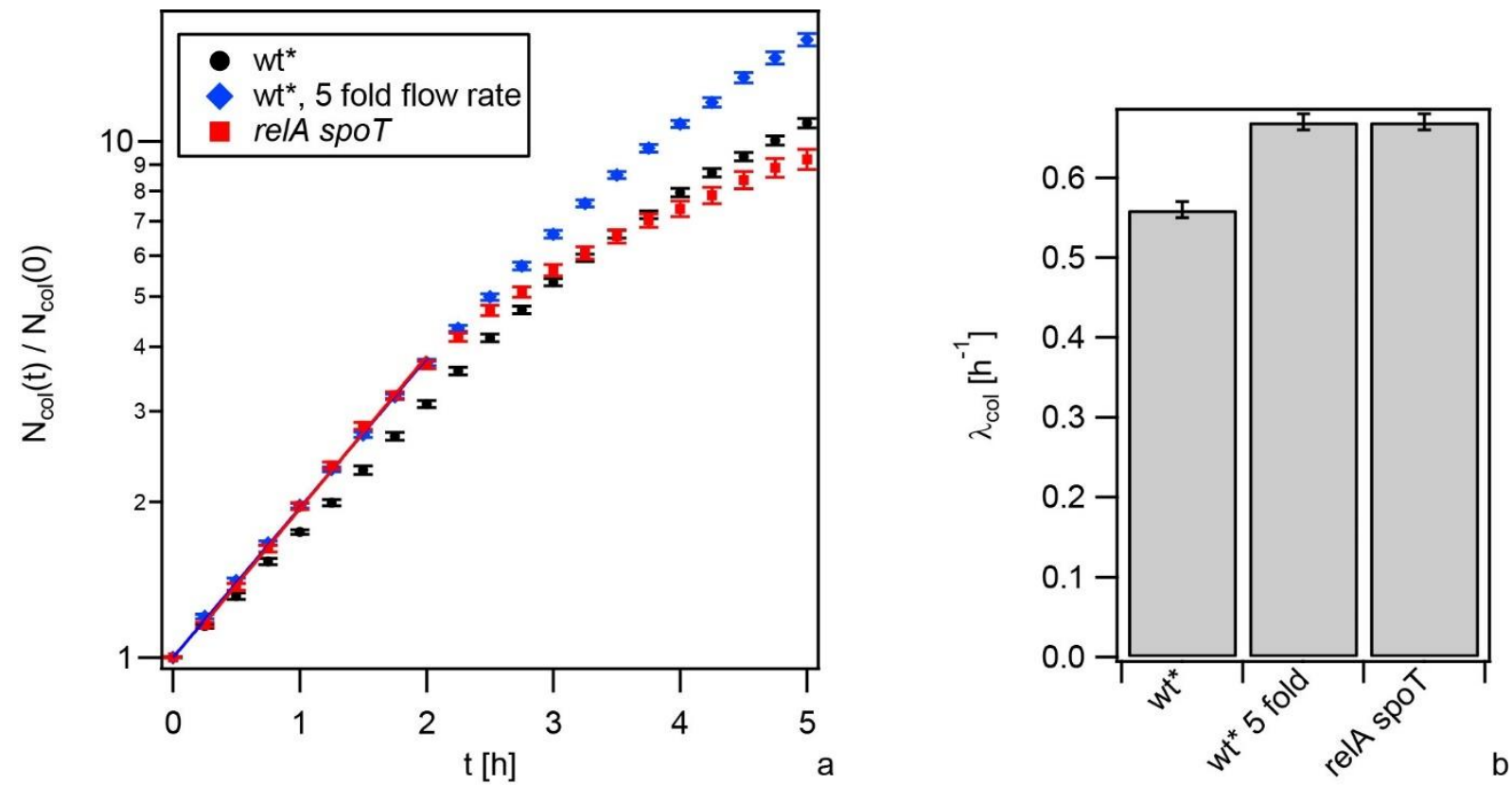

644 Fig. S5 Growth rates determined from colony radius in early colonies for wt* $(\mathrm{Ng} 150)$ and $w t^{*}$ 645 green $(\mathrm{Ng} 194)$ at standard flow rate (black), wt* $(\mathrm{Ng} 150)$ and $\mathrm{wt}^{*}$ green $(\mathrm{Ng} 194)$ at a five-fold 646 increased flow rate (blue), $\Delta r e l A \Delta s p o T(\mathrm{Ng} 198)$ and $\Delta r e l A \Delta s p o T$ green $(\mathrm{Ng} 224)$ at standard 647 flow rate (red). a) Mean number of cells within colony $N_{\text {col }}(t)$ normalized by the number of cells 648 in the colon y at $t=0, N_{\text {col }}(0)$. Full lines exponential fit with $N_{\text {col }}(t) / N_{\text {col }}(0)=\exp \left(\lambda_{\text {colony }} t\right)$. 649 b) Growth rates $\lambda_{\text {col }}$ determined from fits in (a) (mean \pm se, $>40$ colonies for each data point). 
bioRxiv preprint doi: https://doi.org/10.1101/2021.04.27.441609; this version posted April 27, 2021. The copyright holder for this preprint (which was not certified by peer review) is the author/funder, who has granted bioRxiv a license to display the preprint in perpetuity. It is made available under aCC-BY-NC-ND 4.0 International license.

651
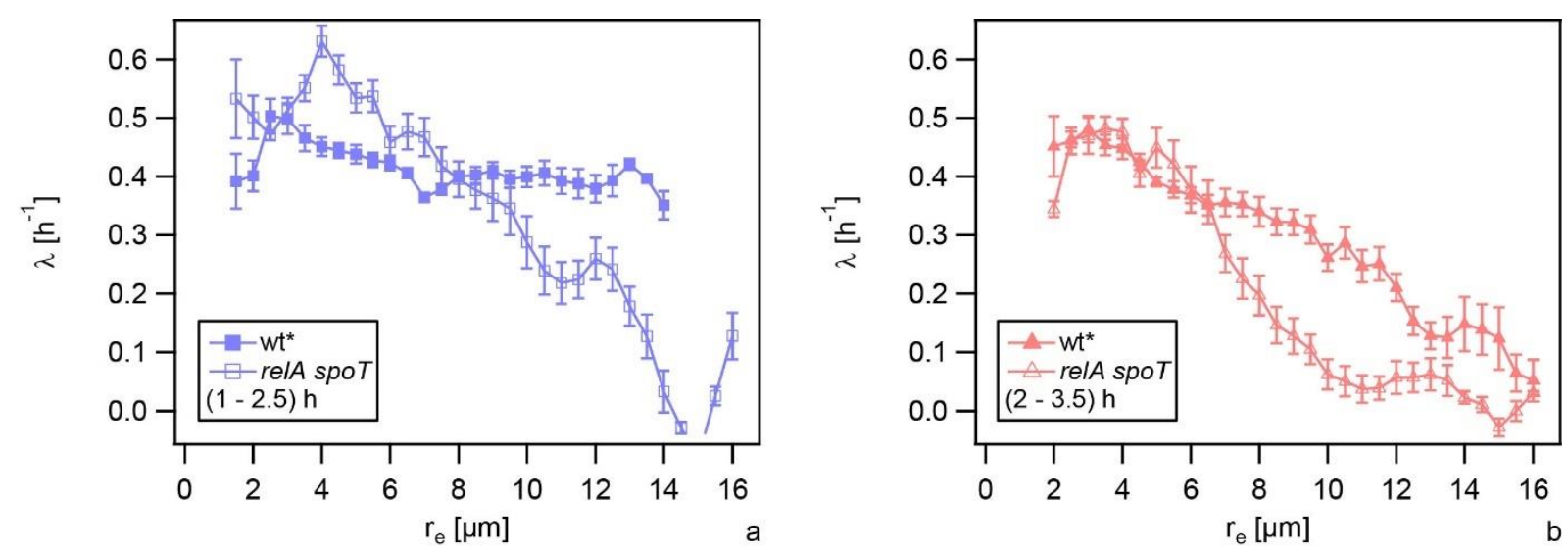

652

Fig. S6 Comparison of growth profiles between wt* and $\Delta r e l A \Delta s p o T$ strains. Mean growth

654 rate $\lambda$ derived by the CC method as a function of the distance $r_{e}$ from the edge of the colony

655 different time intervals $(a, b) . N>10$ clusters for each data point.

656 
bioRxiv preprint doi: https://doi.org/10.1101/2021.04.27.441609; this version posted April 27 2021. The copyright holder for this preprint

(which was not certified by peer review) is the author/funder, who has granted bioRxiv a license to display the preprint in perpetuity. It is made available under aCC-BY-NC-ND 4.0 International license.

\section{Supplementary Tables}

660

\begin{tabular}{|c|c|c|}
\hline Strain & Relevant genotype & Source/Reference \\
\hline$w t *(\mathrm{Ng} 150)$ & $G 4:: a a c$ & (4) \\
\hline$w t^{*}$ green $(\mathrm{Ng} 194)$ & $\begin{array}{l}\text { lctp ::P Pile sfgfp speR::aspC } \\
G 4: \because a a c\end{array}$ & This study \\
\hline ArelA $\triangle$ spoT (Ng198) & $\begin{array}{l}\text { relA::nptII spoT::ermC } \\
\text { G4::aac }\end{array}$ & This study \\
\hline $\begin{array}{l}\text { ArelA } \triangle \text { spoT green } \\
(\mathrm{Ng} 224)\end{array}$ & $\begin{array}{l}\text { relA::nptII spoT::ermC } \\
\text { lctp::P Pile sfgfp speR::aspC } \\
\text { G4::aac }\end{array}$ & This study \\
\hline
\end{tabular}

661

662 Table S1 Bacterial strains used in this study.

663

664

665 